\title{
TRANSPOSIÇÃO MIDIÁTICA: DA SALA DE AULA CONVENCIONAL PARA A PRESENCIAL CONECTADA
}

\author{
FRANCISCO GARONCE* \\ GILBERTO LACERDA SANTOS**
}

\begin{abstract}
RESUMO: O artigo apresenta o conceito de transposição midiática e, para tal, fundamenta-se nos resultados de uma pesquisa acadêmica que identificou os impactos provocados pela tecnologia da videoconferência pela internet, ou webconferência, na ação educativa (modo de ensinar), focando as alterações nos papéis docentes. O estudo de caso etnográfico mostrou de que modo a ação docente foi modificada pela situação educativa na qual alunos e professores interagiram face a face, mediados pela tecnologia, de modo síncrono a distância, caracterizando a educação presencial conectada. A investigação tomou como ponto de partida a teoria da transposição didática dos saberes (Chevallard, 1985), tendo identificado e analisado mudanças na prática docente, especificamente nos papéis docentes, caracterizando o fenômeno da transposição midiática.
\end{abstract}

Palavras-chave: Transposição mediática. Webconferência. Educação a distância. Transposição didática.

\section{MEDIATIC TRANSPOSITION: FROM CONVENTIONAL CLASSROOM TO FACE-CONNECTED CLASSROOM}

ABSTRACT: The focus of this article is to introduce the Mediatic Transposition concept referring to the results of a Brazilian research project that sought to identify impacts of Internet videoconferencing (web conferencing) use in education with an emphasis on the changing role of teachers brought on by this new technology. The ethnographic study identified how the teaching tasks changed when pupils and instructors interacted face to face, mediated by technology, using a synchronous communication tool in a hybrid mode of education. This new educational environment in cyberspace is the face-connected classroom. The research took as its starting point studies related to the Didactic Transposition (Chevallard, 1985) and the research addressed changes in teaching practices that were identified and analyzed, specifically those that

\footnotetext{
* $\quad$ Doutor em Educação pela Universidade de Brasília e pós-doutor em Tecnologias na Educação junto ao Inter-American Defense College. E-mail: garonce.br@hotmail.com

** Ph. D. em Educação pela Universidade Laval (Canadá), Doutor em Sociologia pela Universidade de Brasília, professor da Faculdade de Educação da Universidade de Brasília. E-mail: glacerda@unb.br
} 
impacted on the role of instructors during the transition from conventional to face-connected classrooms characterizing Mediatic Transposition.

Key words: Mediatic transposition. Web conferencing. Distance education. Didactic transposition.

\section{LA TRANSPOSITION MEDIATIQUE: DE LA SALLE DE CLASSE}

CONVENTIONNELLE À LA SALLE DE CLASSE PRESENTIELLE CONNECTÉE

RÉSUMÉ: L'article présente le concept de Transposition Médiatique, à partir d'une recherche académique dont les résultats ont identifié les impacts de la téchnologie de la vidéoconférence par Internet, c'est-à-dire la webconférence, sur l'action éducative (mode d'enseigner) en mettant l'accent sur l'évolution des rôles des enseignants. L'étude de cas, du type ethnographique, a montré la façon dont l'intervention de l'enseignant est modifiée par la situation éducative dans laquelle les étudiants et les enseignants intéragissent face à face, par le moyen de la technologie, de façon syncronisée et à distance. Cela caractérise l'éducation présentielle connectée. La recherche a eu comme point de départ la théorie de la Transposition Didactique (Chevallard, 1985) et a identifié et analysé les changements dans la pratique des enseignants, notamment dans leurs rôles, ce qui caractérise le phénomène de la Transposition Médiatique.

Mots-clés: Transposition médiatique. Webconférence. Éducation à distance. Transposition didactique.

\section{Introdução}

$\mathrm{N}$ as últimas quatro décadas, o computador revolucionou todas as áreas sociais, desde o comércio, a indústria e o lazer, até a educação, modificando a forma como a informação é gerada, tratada e difundida, e afetando diretamente os modos de construção do conhecimento. Os resultados de pesquisa aqui apresentados são decorrentes de uma investigação realizada na Faculdade de Educação da Universidade de Brasília, na qual analisamos um curso de Mestrado Acadêmico a Distância, oferecido para Gestores da Rede Federal de Ensino Tecnológico do Brasil, intitulado Projeto Gestor. A investigação foi motivada pela necessidade percebida no meio acadêmico de entender os efeitos da inserção da videoconferência pela internet, denominada webconferência, no ambiente educacional, ressaltando os impactos provocados por essa tecnologia na relação educativa, na forma de se ensinar e na forma de se aprender, focando as alterações dos papéis docentes neste contexto.

\section{Webconferência}

Vivemos hoje o que Castells (2007) define como "cultura da virtualidade real", na qual se dá uma plena integração das diversas possibilidades de comunicação por 
meio digital e eletrônico, fazendo surgir redes interativas nas quais se forma um supertexto, integrando oralidade e escrita à comunicação audiovisual. Um produto tecnológico capaz de proporcionar a virtualidade real é a webconferência.

Desenvolvida, inicialmente, com o objetivo de promover apenas a comunicação entre pessoas conectadas à rede mundial de computadores através da troca de dados de áudio e vídeo, sincronamente, a webconferência utiliza softwares específicos, dentre os quais se destacam o Skype, o MSN Messenger, o CUSeeMe, o Flash Meeting e o Astor, tendo sido este último desenvolvido pela empresa brasileira Optimedia, atualmente vinculada à Incubadora de Empresas do Centro de Apoio ao Desenvolvimento Tecnológico da Universidade de Brasília (CDT/UnB).

Apesar de alguns destes softwares não terem sido originalmente desenvolvidos com finalidade pedagógica, eles têm sido utilizados em diversas iniciativas de interação didática com um desempenho satisfatório, havendo um considerável número de trabalhos acadêmicos, resultantes de pesquisas empíricas, sobre o tema (Fetterman, 1997; Dixon, 2000; McBride, 2001; McFerrin, 2002; Moonka, 2003; Mahony, 2003; Hausman, 2003; Pemperton, 2004; Xiao, 2005; Tutty, 2007).

A utilização da webconferência como ferramenta de ensino, em ambientes de educação online, tem se difundido amplamente no espaço educacional contemporâneo. Em todo o mundo, esta possibilidade tecnológica vem motivando educadores e gestores de sistemas de ensino a empregá-la, cada vez mais frequentemente, em variadas iniciativas de interação pedagógica. A sala de aula virtual, na qual alunos e professores se vêm e se comunicam de modo síncrono e assíncrono, mediados pela tecnologia, oferece um novo horizonte cheio de potencialidades, mas amplamente recortado por uma série de limitações. Dessa forma, o avanço tecnológico não só se fez presente no espaço da sala de aula, como a modificou completamente, lançando-a no ciberespaço, "um espaço de comunicação aberto pela interconexão mundial dos computadores e das memórias dos computadores" (Lévy, 1999, p. 92), que descarta a necessidade do homem físico para constituir a comunicação como fonte de relacionamento entre as pessoas.

As observações realizadas no âmbito da pesquisa foram feitas através do software Astor, plataforma tecnológica adotada para o Projeto Gestor. O Astor é uma tecnologia de comunicação multimídia e multiponto em tempo real, com modelo de gestão próprio e funcionalidades como transmissão de áudio/vídeo, transferência de arquivos, captura de tela, mensagens instantâneas, lousa, chat, slides, gravação e reprodução de áudio/vídeo, enquetes e editor de texto compartilhado. Foi concebido com o objetivo de promover webconferências com transmissão simultânea de dados e aplicação em ambientes educacionais, tendo integração e conectividade com as plataformas de padrões mundiais. 
Para acessar o Astor, alunos e professores não necessitam baixar o programa (realizar o download) em seus computadores, havendo apenas a necessidade de estarem conectados à rede mundial de computadores, preferencialmente utilizando conexões com boa capacidade de transmissão de dados. O software oferece uma série de ferramentas que podem ser empregadas para dinamizar a interação presencial conectada, tais como a construção colaborativa de textos, a apresentação de slides do PowerPoint, de vídeos, compartilhamento de arquivos digitais e imagens, aplicação de enquetes, chat online, demonstrações em uma lousa virtual, além do contato face a face, mediado pela tecnologia, entre alunos e professores. $\mathrm{O}$ endereço eletrônico para acessar a sala de aula virtual do Astor, que oferece uma demonstração das suas funcionalidades, é: <http://www.optimedia.com.br>.

A relação de ensino que se estabelece entre alunos e professores na sala de aula virtual - onde a ferramenta de ensino empregada é a webconferência - é presencial conectada, que se difere em muitos aspectos da relação tradicional que se processa na sala de aula convencional, à qual estamos habituados, sendo diferente também da relação estabelecida nos sistemas tradicionais de educação a distância. Nessa modalidade de educação, professores e alunos comunicam-se em tempo real e mantêm contato face a face, mediados pela tecnologia.

Agora que fizemos a apresentação da webconferência como ferramenta educativa e da relação educativa presencial conectada, é importante que entendamos a Teoria da Transposição Didática dos saberes, para que possamos, posteriormente, compreender o conceito de transposição midiática.

\section{Transposição didática}

A Teoria da Transposição Didática dos saberes foi desenvolvida na década de 1980 pelo educador francês Chevallard (1985) e apresentou uma nova forma de compreensão da relação didática que deixou para trás uma abordagem "ensinanteensinado", muito adotada até o seu surgimento, para inserir um novo elemento de análise na relação, "o saber", tornando-a ternária. Docentes, alunos e saberes passaram a ser os elementos constitutivos do sistema didático proposto.

$\mathrm{O}$ "saber" que Chevallard inseriu na análise do sistema didático recebeu a denominação de "saber ensinado", ou seja, aquele que é efetivamente transmitido pelos professores, nos ambientes escolares. Vale ressaltar que dentro do sistema escolar há também o "saber a ser ensinado", ou seja, aquele saber determinado pelos manuais que orientam os professores a respeito dos conteúdos programáticos a serem ministrados, que reflete as expectativas da sociedade em relação ao sistema 
escolar; existe ainda o "saber a ser aprendido", resultante da expectativa do professor em relação aos seus aprendizes, a partir do ensino oferecido.

Entre os três saberes que se apresentam no sistema escolar (saber a ser ensinado, saber ensinado, saber a ser aprendido), a atenção é focada no "saber ensinado", pois é o que realmente se efetiva. Este, no entanto, difere do que Chevallard denominou, em francês, o Savoir savant, que traduzimos para o português como o "saber sábio", o saber científico ou acadêmico, produzido no seio da comunidade científica.

Uma importante contribuição desta teoria foi o esclarecimento sobre a necessidade de que o conteúdo do saber sábio sofra recortes e "deformações" para que possa ser tratado no ambiente escolar, tornando-o apto a ser ensinado.

O saber ensinado acaba sendo um saber exilado de suas origens e separado de sua produção histórica, que está na esfera do saber sábio. Isto se dá em função da série de ajustes, recortes e ressignificações pelas quais o saber passa até chegar ao sujeito aprendiz. Mesmo atravessando todo este processo que o afasta de sua origem, a sociedade o reconhece e lhe confere valor, legitimando-o através da autoridade da escola. Diante de tão significativas mudanças, os saberes ensinados passam a ser considerados avatares didáticos do saber sábio que lhes deu origem.

As atuais disciplinas denominadas "Matemática Geral”, "Física Geral” e "Química Geral" são o resultado do processo da transposição didática pelo qual o saber científico original passou para chegar a um saber ensinável, resultado de uma junção de diversos recortes do saber, com uma composição heteróclita do seu conteúdo e cuja unidade seria somente a intenção didática que lhe deu origem.

Esta intenção didática está inserida no cerne da escola e um aspecto que não pode ser esquecido é que ela está no centro da vida das sociedades. A trajetória escolar, nesse sentido, é uma visita guiada, mais ou menos imposta, aos fundamentos epistemológicos do todo social; um tributo que pagamos coletivamente para o funcionamento das nossas sociedades. O ponto de partida das escolas são as práticas sociais, as quais a escola, através dos saberes que se procura ensinar nelas, tem como missão manter, enriquecer, desenvolver e fortalecer. Afinal, a escola é o coração da sociedade e é importante que ela seja entendida dentro deste contexto.

O recorte (transposição didática) que se faz a partir de um saber mais extenso pode ser comparado a uma caricatura, onde ocorre uma substituição didática do objeto. Sabemos que ela não retrata fielmente o objeto, mas nos dá uma perfeita noção dele, realçando os aspectos que o seu autor considera mais importantes. Ao vermos uma caricatura de certas figuras públicas temos a certeza de quem se trata, mesmo sabendo que ela não é uma cópia fiel do indivíduo caricaturizado. Trazendo isso para o campo da sala de aula, teremos a situação em que um cientista 
pesquisador da área atômica, ao assistir a uma explicação dada por um professor do ensino fundamental a respeito de moléculas, átomos e elétrons, perceberá que muitos aspectos relativos àquele tema foram suprimidos da explicação dada aos alunos, mas perceberá que a explicação dada corresponde genericamente ao que a maioria dos integrantes da comunidade científica considera verdadeiro, podendo contextualizar aquilo que é ensinado e torná-lo ainda mais próximo da realidade.

Questões relacionadas à prática pedagógica são fundamentais neste processo, mas isoladas também não são suficientes. É através do trabalho de associação do seu conhecimento de regulação, intermediação e na perspectiva dos objetivos pedagógicos que o professor fará uso do conhecimento a ser abordado, referindo-se à sua essência epistemológica, e promoverá a interação com aquilo que o aluno já possui de conhecimentos para que se estabeleça aí uma relação didática. Este processo faz parte da transposição didática, como sendo o trabalho de transformar um conteúdo científico em um objeto a ser ensinado.

A Teoria da Transposição Didática veio responder questionamentos tais como: "De onde vêm os saberes ensinados? Das instituições de produção do saber. Como chegam às instituições didáticas? Pelo processo da transposição didática" (Chevallard, 1985, p. 65).

Veremos, mais adiante, como a Teoria da Transposição Didática dá suporte à compreensão do fenômeno da transposição midiática. Agora, no entanto, cabe-nos apresentar o caminho metodológico percorrido, a fim de produzir este trabalho acadêmico.

\section{Método de investigação}

A opção metodológica adotada na investigação aqui relatada foi por um estudo de caso com aporte etnográfico, cujo quadro operacional incluiu observação participativa, entrevistas e pesquisa documental, com ênfase na observação participativa e entrevistas formais e informais, tomando como referência inicial para o trabalho de campo quatro categorias analíticas, relacionadas aos papéis docentes em situações de educação online: papel pedagógico, papel social, papel gerencial e papel tecnológico (Berge, 1995; Hutton, 1996; Anderson, 2001; Johansson, 2005). Estas categorias se mostraram tão satisfatórias no transcorrer do trabalho investigativo, a ponto de não ter sido necessário acrescentar qualquer outra, dentro de um modelo misto inicialmente proposto.

A opção pelo estudo de caso deu-se pela possibilidade de investigar exaustivamente um caso em particular, a fim de entendê-lo como instância singular que, ao mesmo tempo em que possui dinamismo próprio, está inserida em uma realidade 
maior. Estudamos a unidade em suas especificidades. Porém, isto não nos impediu de estarmos atentos ao contexto em que aquela situação específica estava inserida, nem às relações decorrentes de seu entorno. O estudo de caso foi "o retrato vivo da situação investigada, tomada em suas múltiplas dimensões e em sua complexidade própria" (André, 1995).

Decidimos por uma pesquisa de aporte etnográfico, pois percebemos que ela se adequava perfeitamente às condições com as quais trabalharíamos durante a investigação. Por dois anos, de 2007 a 2009, foram realizadas observações junto ao Projeto Gestor, tanto como observador externo, sem participação efetiva nas aulas, como no papel de tutor, interagindo com professores, alunos e técnicos responsáveis pela implantação do software Astor, da sala de aula virtual.

Durante essas observações, estivemos fisicamente presentes no Laboratório de Informática da Faculdade de Educação da UnB, nos momentos em que ocorreram as aulas presenciais conectadas, para observar in loco a atuação dos professores e, através da interação por meio da webconferência, o comportamento dos sujeitos aprendizes, alunos do Projeto Gestor.

O fato de pesquisador, professores e alunos estarem fisicamente separados, porém presencialmente conectados pela tecnologia, não impediu, de forma alguma, a condução de uma pesquisa etnográfica na sala de aula virtual, que teve o seu "lugar" claramente demarcado no ciberespaço.

Pode-se considerar que utilizamos o procedimento metodológico da etnografia virtual (Hine, 2000) que tem sido usada para pesquisar interações online que fazem uso de variados suportes. Segundo Hine (2000), a etnografia virtual pode ser usada para desenvolver a percepção do sentido da tecnologia e dos espaços socioculturais que são por ela estudados - no caso da nossa pesquisa, foram a webconferência e a sala de aula virtual.

Fizemos o acompanhamento das disciplinas do curso de Mestrado Acadêmico a Distância da Faculdade de Educação da Universidade de Brasília, oferecido para Gestores da Rede Federal de Ensino Tecnológico do Brasil, intitulado Projeto Gestor, oferecidas por meio de webconferência. O grupo pesquisado foi composto por 42 alunos e oito professores do programa de pós-graduação da Universidade, diretamente envolvidos.

O enfoque holístico tornou-se evidente quando da descrição das experiências junto ao Projeto, pois empregamos considerável esforço no sentido de buscar identificar todo o sistema de relações sociais e padrões culturais do grupo pesquisado.

É importante ressaltar que o ideal do holismo na descrição etnográfica acabou se mostrando algo inatingível, devido a sua excessiva extensão, decorrente da 
complexidade do que pretendemos compreender. Por mais que tivéssemos a intenção de observar e registrar todas as variantes envolvidas no processo de ensino e aprendizagem, focando a atenção nos impactos sobre a ação docente decorrentes da utilização da webconferência como ferramenta pedagógica, mostrou-se meta inalcançável perceber tudo o que ocorria, em virtude do número expressivo de interações que acabavam acontecendo ao mesmo tempo, através de diversos canais (falas individuais, interações pelo chat, mensagens postadas durante a aula, enquetes que ocorriam de modo paralelo à aula, imagens dos atores envolvidos, vídeos, imagens de slides, entre outros). Diante da complexidade das relações educativas e das limitações humanas do pesquisador, a opção feita foi pelo possível, largamente ampliado pelas ferramentas tecnológicas que possibilitaram revisitar inúmeras vezes as aulas presenciais conectadas que ficaram arquivadas na plataforma Astor.

A pesquisa junto aos professores e alunos do Projeto Gestor ocorreu de janeiro de 2007 a março de 2009, sendo que, do início dos trabalhos até dezembro de 2008, foram feitas observações sem a participação direta do pesquisador na aula, momentos estes em que o pesquisador se manteve conectado à aula por webconferência, através do Astor, porém os alunos não se davam conta de que estavam sendo observados; os professores sabiam disso, pois compartilhavam o laboratório de informática da Universidade com o pesquisador, durante a aula. Já durante o segundo semestre de 2007 e primeiro e segundo semestres de 2008, o pesquisador atuou como tutor em três diferentes disciplinas, quando tivemos a oportunidade de realizar efetivamente uma observação participante, momentos nos quais os alunos eram esclarecidos a respeito da atuação do pesquisador naquele ambiente educativo.

Foram analisadas mais de 150 aulas e interações entre professores e alunos, nos momentos em que se efetivava a relação presencial conectada. $\mathrm{O}$ banco de dados do software Astor, gerenciado pela Optimedia, tem registrado em seus arquivos um total de mais de 303 horas de gravações de áudio e vídeo, sendo que deste total são mais de duzentas horas de efetivas aulas.

Após termos registrado e organizado todos os dados coletados entre março de 2007 e dezembro de 2008, passamos então a uma revisão extensiva, com o objetivo de descobrir os padrões recorrentes, os casos discrepantes e os princípios subjacentes de comportamento. A questão básica quando da análise dos dados foi estabelecer o contraste identificado ao longo das linhas analíticas adotadas. Como a pesquisa teve por objetivo Identificar os impactos da utilização da webconferência como ferramenta de ensino sobre os papéis docentes em um ambiente de educação presencial conectada, esta foi a linha mestra a partir da qual as análises foram feitas, tomando como base o referencial teórico adotado.

Dessa forma, pudemos analisar os resultados e chegar a significativas conclusões, que foram checadas através de entrevistas realizadas em março de 2009, tendo 
sido possível colher as impressões e depoimentos de mais de 50\% dos docentes e alunos que atuaram nas aulas presenciais conectadas.

Assim sendo, o valor da descrição etnográfica foi maior, ao combinar seu interesse em amplitude e generalidades com sua atenção ao específico e concreto e, ao agir desta forma, fizemos uso deliberado de métodos múltiplos de coleta de dados e de modos variados de descrição e análise, tendo sido este o nosso procedimento durante a condução da pesquisa etnográfica, cujos principais resultados, que passaremos a apresentar, nos levaram à identificação do fenômeno da transposição midiática.

\section{Resultados da pesquisa: impactos da tecnologia da webconferência sobre os papéis docentes}

O principal resultado identificado com a pesquisa refere-se à identificação dos impactos provocados pela tecnologia da webconferência na forma de se ensinar. Vale ressaltar que entendemos como impactos as alterações e ajustes ocorridos na relação educativa, que se estabeleceu de um modo diferente daquela que ocorre nos momentos de educação tradicional (sala de aula convencional), em função da utilização dessa nova possibilidade tecnológica de interação.

Tendo em vista que o foco da pesquisa esteve na atuação do professor junto aos seus alunos, em um ambiente pedagógico da sala de aula virtual, cuja ferramenta de ensino foi a webconferência, houve a necessidade de estabelecermos algumas categorias dentro das quais pudemos identificar os papéis desempenhados pelo professor. Para tanto, adotamos os mesmos critérios de observação de outros pesquisadores (Berge, 1995; Hutton, 1996; Anderson, 2001; Johansson, 2005), definindo os papéis desempenhados pelos professores, quando atuando em ambientes síncronos do ciberespaço, como sendo divididos em quatro categorias: papel pedagógico, papel social, papel gerencial e papel técnico.

O papel pedagógico é aquele ao qual os educadores estão mais acostumados nas suas atividades profissionais cotidianas e cuja principal função é a de ser um facilitador através da definição dos objetivos educacionais a serem alcançados, os conteúdos a serem abordados e as estratégias que serão adotadas com os alunos.

O papel social é relacionado à responsabilidade que o docente tem de criar condições para que se estabeleça um clima amigável entre os alunos e que estes interajam, ainda que afastados fisicamente, fazendo com que se sintam próximos e com liberdade para estabelecer relações de amizade, criando um clima de coesão no grupo. O professor deverá, ao desempenhar este papel, ajudar os alunos a desenvolverem a capacidade de trabalhar em grupo, ainda que virtualmente, e incentivá-los a se ajudarem. 
O papel gerencial é relacionado à administração, por parte do docente, de todas as situações e atividades do curso em relação ao tempo programado, conduzindo as situações inusitadas, sendo claro quanto às atividades docentes e discentes, as regras acadêmicas, prazos limites e as normas do curso às quais todos estarão sujeitos.

O papel técnico é, em suma, fazer com que os alunos sintam-se confortáveis em relação à tecnologia empregada, especialmente quanto à utilização do software. O objetivo do docente deve ser o de fazer com que a tecnologia seja a mais "transparente" possível, ou seja, que os estudantes possam se concentrar nos conteúdos que estarão sendo abordados e que o aparato tecnológico seja apenas um meio através do qual todos estarão conectados.

Os resultados da pesquisa apontaram que, quanto aos papéis pedagógicos, os impactos da utilização da webconferência estão relacionados à necessidade que o docente passa a ter de adquirir habilidades comunicativas em uma nova mídia; de perceber a verdadeira dimensão da sala de aula virtual e o posicionamento dos seus alunos no ciberespaço; de planejar efetivamente as aulas, de modo detalhado, considerando todas as variantes tecnológicas possíveis; de primar pela brevidade, objetividade e simplicidade do discurso, a fim de manter os alunos ligados à aula; de adotar dinâmicas que envolvam os alunos nas discussões do ambiente online; de desenvolver estratégias inovadoras de integração de ferramentas assíncronas, como o Moodle, que facilitem a construção de comunidades colaborativas de ensino e aprendizagem em rede; e de estabelecer uma dinâmica hipertextual para lidar com os alunos presenciais conectados.

Quanto aos papéis sociais, os impactos da utilização da webconferência estão relacionados à necessidade que o docente passa a ter de estar atento à sua responsabilidade de integrar os alunos e de desenvolver estratégias docentes que reforcem o sentimento de grupo social na sala de aula virtual.

Quanto aos papéis gerenciais, os docentes passaram a depender fundamentalmente do suporte tecnológico, de um modo nunca antes experimentado; precisaram adequar-se às novas ferramentas tecnológicas, que inexistiam na sala de aula convencional; foram impelidos a desenvolver novos canais de percepção em relação aos alunos presenciais conectados; perceberam a necessidade de reestruturar a forma de estabelecer as suas relações gerenciais com os alunos, abandonando o formato linear e adotando o modelo hipertextual; tiveram que adequar os tempos de suas aulas, em função do desgaste provocado pela mediação tecnológica; e, consequentemente, tiveram a sua carga de trabalho aumentada consideravelmente, a fim de atender as novas demandas.

E quanto aos papéis técnicos, os docentes perceberam que, na educação presencial conectada, estes passam a ser fundamentais, não podendo ser negligenciados de 
forma alguma pelo docente, sob o risco de inviabilizarem completamente a relação educativa, em virtude de estarem na base da comunicação entre alunos e professores.

\section{Discussão dos resultados: a transposição midiática}

Pudemos constatar, a partir dos resultados aos quais chegamos, que o comportamento docente foi impactado pela inserção da webconferência na relação educativa, modificando a forma de trabalhar os saberes junto aos alunos.

Ao processo de transposição das ações docentes do ambiente tradicional para o virtual, com o estabelecimento da relação presencial conectada, possibilitada pela webconferência, denominamos "transposição midiática". Contudo, como o conceito de transposição didática dá suporte ao de transposição midiática?

O conceito da transposição didática (Chevallard, 1985) refere-se a um fenômeno, que é a transposição, e a um ponto de chegada, que é o didático. O que identificamos com a pesquisa realizada, que foi a transposição midiática também faz referência a um fenômeno, que é a transposição, e a um ponto de chegada, que é o didático. Porém, este processo foi decorrente da mudança do meio onde ele acontece, ressaltando a mediação tecnológica.

Então, a transposição midiática seria a própria transposição didática? Não. Podemos considerar que a transposição midiática está inserida em um extenso contexto dentro do qual se dá a transposição didática; porém, ela se apresenta como uma transposição didática de segunda ordem, sendo metodológica e não epistemológica.

O conceito elaborado por Chevallard (1985) faz referência a uma mudança de natureza epistemológica, relativa ao conhecimento, que antes era científico, ou sábio, e se torna didático, ensinável. No caso da transposição midiática, o conhecimento já estava didatizado e assim permaneceu. A transposição que identificamos não foi epistemológica, mas metodológica. Portanto, podemos considerar a transposição midiática como um fenômeno que se caracteriza por um conjunto de recortes e ajustes, influenciado por fatores humanos e tecnológicos, que foram apresentados, sendo uma transposição de ações educativas da sala de aula presencial convencional para a sala de aula virtual, onde se estabelece a relação presencial conectada, possibilitada pela webconferência.

Fizemos ampla investigação bibliográfica junto às produções acadêmicas nacionais em busca de trabalhos científicos que abordassem temas correlatos à nossa pesquisa. No entanto, não foi possível identificar referências que dessem suporte à nossa linha argumentativa, que apresentassem considerações divergentes ou com a qual pudéssemos estabelecer um diálogo sobre o tema. 


\section{Conclusão}

Uma constatação a que chegamos foi a respeito da necessidade de que se estabeleça um modelo de formação para professores que irão atuar em ambientes virtuais de educação online, utilizando a webconferência, a fim de prepará-los para a transposição midiática. Afinal, a formação do professor no passado e na atualidade não o tem preparado para exercer plenamente todos os papéis que lhe são agora demandados.

No momento, os professores se encontram numa fase de transição, ensinando o mesmo currículo de duas maneiras completamente diferentes: através do modo presencial e através das redes de aprendizagem, nas quais a interação é totalmente online. Para ensinar online, é necessário um conjunto diferente de técnicas, é preciso ser um facilitador de discussões em grupo (Ferreira \& Lacerda Santos, 2009). Embora os professores continuem precisando conhecer sua matéria, isso não é suficiente (Teles et al., 2005).

As observações feitas junto ao Projeto Gestor indicam que a webconferência é uma excelente ferramenta educativa, capaz de promover ambientes de profícua aprendizagem, pois o professor tem como manter contato face a face com seus alunos durante a aula online e, a partir de uma transposição midiática de qualidade, promover um ambiente educativo de qualidade.

Um professor que seja desafiado a atuar em uma arena educativa presencial conectada e esteja interessado em promover uma transposição midiática de qualidade deverá estar atento às variantes relacionadas aos papéis que ele desempenhará neste novo ambiente. Diante dos resultados da pesquisa, a fim de ajudar os professores interessados em melhor atuar neste novo contexto, elaboramos dez perguntas básicas, fundamentais à reflexão dos docentes sobre o seu desempenho no processo da transposição midiática:

1. O professor está apto a gerenciar as ferramentas tecnológicas da sala virtual?

2. O professor tem consciência da importância do seu papel técnico, que pode inviabilizar completamente a comunicação e, consequentemente, a aula?

3. Existe uma preparação para a aula, como se fosse a preparação para um programa de tevê, ao vivo, interativo?

4. Quando prepara a sua aula, o docente tem como meta ser breve, objetivo e simples na sua comunicação com os alunos? 
5. Ao planejar a aula, o professor adota uma sequência rígida, a ser obrigatoriamente seguida por todos os alunos, ou opta por um modelo flexível, hipertextual?

6. O tempo destinado às aulas presenciais conectadas é suficiente para cobrir todo o conteúdo e manter os alunos interessados?

7. Existe uma consciência a respeito da responsabilidade do docente em integrar socialmente os alunos e promover o espírito de grupo na classe?

8. Os professores têm condições de elaborar um mapa mental da sua sala de aula virtual presencial conectada, durante o momento em que ela está acontecendo?

9. O docente está em condições de perceber as necessidades e intenções de todos os alunos conectados no momento da aula?

10. Como ficará a carga de trabalho do docente para que ele conduza efetivamente uma transposição midiática de qualidade?

Refletindo sobre cada uma destas questões apresentadas, é possível, para todos os que se interessam por esta possibilidade tecnológica de educação, chegar a uma variada gama de possibilidades para a transposição midiática.

É fundamental que os educadores continuem a adotar uma atitude positiva em relação aos desafios que as tecnologias apresentam, a fim de desvendar todas as possibilidades dentro do novo paradigma que se descortina. O espaço está aberto ao desenvolvimento de múltiplas experimentações, expressões e montagem de conexões em rede, que permitam novas e múltiplas formas de fazer com que a transposição midiática se dê de forma plena e com qualidade. Não há dúvidas de que, para cada uma das questões apresentadas, as possibilidades de respostas são muitas. E muito mais importante que as respostas em si é o exercício da reflexão.

\section{Referências}

ANDERSON, T. Assessing teaching presence in a computer conferencing context. Journal of Asynchronous Learning Networks, v. 5, n. 2, p. 1-17, 2001.

ANDRÉ, M.E.D. Etnografia da prática escolar. São Paulo: Papirus, 1995.

BERGE, Z.L. Facilitating computer conferencing: recommendations from the field. Educational Technology, Englewood, v. 35, n. 1, p. 22-30, 1995.

CASTELLS, M. Sociedade em rede. São Paulo: Paz \& Terra, 2007. 
CHEVALLARD, Y. La transposition didactique: du savoir savant au savoir enseigné. Grenoble: Pensée Sauvage, 1985.

CRUZ, D.M.; BARCIA, R.M. Educação a distância por videoconferência. Tecnologia Educacional, Rio de Janeiro, v. 28, n. 150/151, p. 3-10, 2000.

DIXON, R.S. Internet videoconferencing: coming to your campus soon! Educause Quarterly, v. 1, n. 4, p. 22-27, 2000.

FERREIRA, D.J.; LACERDA SANTOS, G. Scaffolding online discourse in collaborative ill-structured problem-solving for innovation. Informatics in Education, v. 8, n. 2, p. 173-190, 2009.

FETTERMAN, D.M. Videoconferencing over the internet. Qualitative Health Journal, v. 7, n. 1, p. 154-163, 1997.

HAUSMAN, R. Using desktop videoconferencing and multimedia modules to convert existing master's degree in educational diagnostics to a successful interactive, internet-based program for rural bilingual educators. In: CRAWFORD, C. et al. (Ed.). Proceedings of Society for Information Technology and Teacher Education International Conference. Chesapeake: AACE, 2003. p. 366-369.

HINE, C. Virtual ethnography. London: Sage, 2000.

HINE, C. Virtual methods and the sociology of cyber-social-scientific knowledge. In: HINE, C. (Org.). Virtual methods: issues in social research on the internet. New York: Berg, 2005.

HUTTON, S.; WIESENBERG, F. Teaching a graduate program using computer-mediated conferencing software: distance education futures. Journal of Distance Education, Ottawa, v. 11, n. 1, p. 1-15, 1996.

JOHANSSON, J. Seminars in cyberspace?: teachers experiences of using synchronous web seminars in distance education. Recent Research Developments in Learning Technologies, 2005.

LÉVY, P. Cibercultura. São Paulo: Editora 34, 1999.

MAHONY, M.; SULLIVAN, T.; McSHANE, K. Synchronous desktop conferencing (SDC): exploring the potential for support of students in professional/clinical placements and research settings, and for collegial. In: ROSSETT, A. (Ed.).Proceedings of World Conference on E-Learning in Corporate, Government, Healthcare and Higher Education. Chesapeake: AACE, 2003. p. 619-622.

MCBRIDE, R.; FULLER, F.; GILLAN, R. Desktop video conferencing: the optimum solution for synchronous distance learning. In: PRICE, J. et al. (Ed.). Proceedings of 
Society for Information Technology and Teacher Education International Conference. Chesapeake: AACE, 2001. p. 245-250.

MCFERRIN, K.; FURR, P. Learning in online and desktop video conferencing courses: are some students plugged in and tuned out? In: WILLIS, D. et al (Ed.). Proceedings of Society for Information Technology and Teacher Education International Conference. Chesapeake: AACE, 2002. p. 255-259.

MOONKA, R. Virtual labs: the latest in technical training over the internet. Distance Learning \& Training, v. 1, n. 4, p. 3-5, 2003.

PEMBERTON, J. et al. Desktop videoconferencing system: a tool for supervising university students at a distance. In: Proceedings of Society for Information Technology and Teacher Education International Conference. Chesapeake: AACE, 2004. p. 4942-4943.

TELES, L. et al. Redes de aprendizagem. Um guia para ensino e aprendizagem on-line. Trad. Ibraíma Dafonte Tavares. São Paulo: Senac, 2005.

TUTTY, J.; DAWLEY, L. Desktop video conferencing in e-learning. In: CARLSEN, R. et al (Ed.). Proceedings of Society for Information Technology and Teacher Education International Conference. Chesapeake: AACE, 2007. p. 2114-2120.

XIAO, M.; YANG, X. The effects of internet-based desktop videoconference on EFL students oral skills in terms of linguistic accuracy, fluency and complexity. In: KROMMERS, P.; RICHARDS, G. (Ed.). Proceedings of World Conference on Educational Multimedia, Hypermedia and Telecommunications. Chesapeake: AACE, 2005. p. 882-885.

Recebido em 22 de setembro de 2011.

Aprovado em 17 de outubro de 2012. 